\title{
Zoledronic acid, a third-generation bisphosphonate, inhibits cellular growth and induces apoptosis in oral carcinoma cell lines
}

\author{
TAKAYUKI TAMURA ${ }^{1,2}$, KOHEI SHOMORI ${ }^{1}$, MOTOKI NAKABAYASHI $^{2}$, \\ NOBUYUKI FUJII ${ }^{2}$, KAZUO RYOKE ${ }^{2}$ and HISAO ITO $^{1}$ \\ ${ }^{1}$ Division of Organ Pathology, Department of Microbiology and Pathology, Faculty of Medicine, Tottori University, Tottori; \\ ${ }^{2}$ Division of Oral and Maxillofacial Biopathological Surgery, Department of Medicine of Sensory and Motor Organs, \\ School of Medicine, Tottori University Faculty of Medicine, Yonago 683-8503, Japan
}

Received October 23, 2010; Accepted December 3, 2010

DOI: $10.3892 /$ or.2011.1152

\begin{abstract}
Bisphosphonates (BPs) inhibit bone resorption by preventing osteoclast maturation and apoptosis induction. Recently, BPs have also been shown to have antitumor effects against various types of carcinomas in vitro and in vivo. In this study, we investigated the antitumor effect of zoledronic acid (ZOL), a third generation bisphosphonate, on proliferation, cell cycle and apoptosis of oral cancer cells. Direct antitumor effects of ZOL against four oral carcinoma cell lines (squamous cell carcinoma, HSC3, HSC4, SCCKN; salivary adenocarcinoma, HSY) were measured by WST assay. Apoptosis-related molecules were analyzed by Western blot analysis and cell cycle was analyzed by flow cytometry. ZOL had a dose-dependent antitumor effect in the four oral cancer cell lines. ZOL activated caspase-3, -8 and -9 and induced cellular apoptosis. Western blot analysis showed that ZOL increased cleaved anti-human poly(ADP-ribose) polymerase expression and decreased Bcl-2 and Bid expression. Treatment with ZOL increased the number of cells in apoptosis, sub G1 phase and S phase, and reduced the number of cells in the G0/G1 and G2/M phase in a concentrationdependent manner. ZOL inhibits cell proliferation and induces apoptosis of oral cancer cells in vitro. These findings suggest that ZOL might be beneficial in the treatment of oral carcinoma patients.
\end{abstract}

\section{Introduction}

Oral cancer, especially squamous cell carcinoma (OSCC), has a relatively high rate of recurrence and poor prognosis

Correspondence to: Dr Takayuki Tamura, Division of Organ Pathology, Department of Microbiology and Pathology, Faculty of Medicine, Tottori University, 86 Nishi-cho, Yonago, Tottori 683-8503, Japan

E-mail: tamura26@med.tottori-u.ac.jp

Key words: zoledronic acid, oral carcinoma, cell cycle, apoptosis because of nodal and distant metastases (1-4). Although recent advances in radio and/or chemotherapy have improved patients' quality of life, the relative 5-year survival rate has not significantly changed (5). Thus, more effective therapeutic strategies against oral cancers are necessary. A few studies have found that mandibular invasion of oral cancer especially OSCC predicts poor prognosis (6). Rao et al reported that the frequency of mandibular invasion of oral carcinomas ranged from 12 to 56\% (7). Clinically, bone destruction in SCCs causes many problems regarding the function and prognosis of patients. Bone invasion in OSCCs is a critical determinant of the postoperative functional outcome. So, it is very important to develop new treatments for bone invasion by oral carcinomas.

Bisphosphonates (BPs) are structural analogs of pyrophosphoric acid, a biomedical component. They are potent inhibitors of osteoclastic bone resorption. They have been used for treatment of osteoporosis, Paget's disease, and cancer-induced hypercalcemia $(8,9)$. BPs can be divided into three generation based on differences in the structure of the $R_{1}$ side chain. The first generation of BP contains no nitrogen, while the second generation of $\mathrm{BP}$ contains nitrogen in the $R_{1}$ side chain. The third generation of $B P$ contains nitrogen in circular structure. Zoledronic acid (ZOL) is a nitrogen-containing BP classified as a third-generation of $\mathrm{BP}$ that has greater potential for anti-osteoclastic bone resorption than second-generation BPs (10). The nitrogencontaining BPs inhibit protein prenylation in osteoclasts and can induce apoptosis (11).

Recently, BPs have presented in vitro and in vivo producing direct antitumor activity in a variety of malignant tumors (12-15). However, the effect of BPs on oral cancers is not so manifested. In our study, we demonstrated the antitumor effect of ZOL on the proliferation, cell cycle and apoptosis of oral cancer cell lines.

\section{Materials and methods}

Reagents. ZOL was kindly provided as the hydrated disodium salt, molecular weight 401.6, by Novartis Pharma AG (Basel, Switzerland), dissolved in phosphate-buffered saline and stored as a $10 \mathrm{mM}$ stock solution at $-20^{\circ} \mathrm{C}$ for in vitro experiments. 

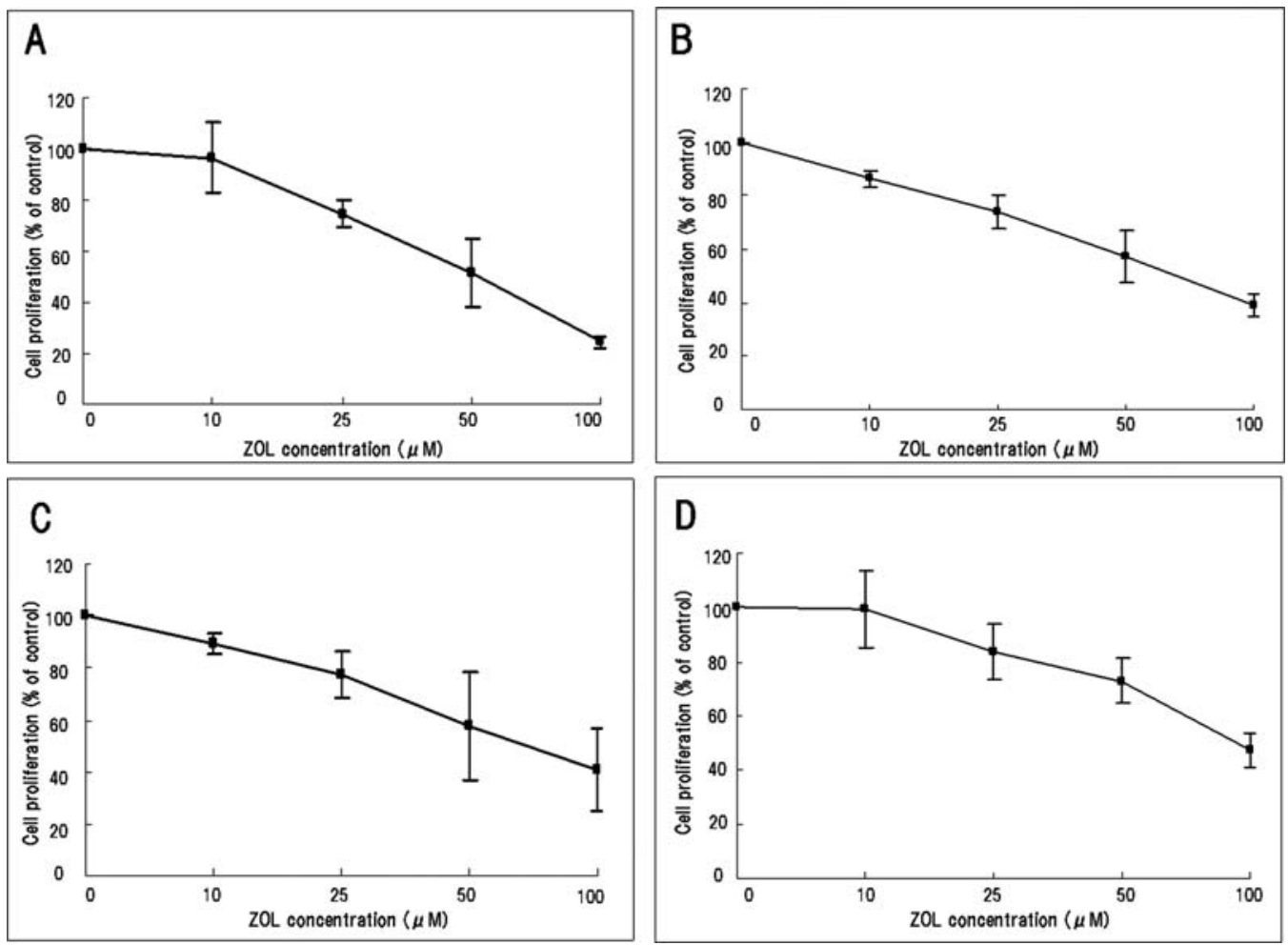

Figure 1. Direct effect of ZOL on four oral carcinoma cell lines HSC-3 (A), HSC-4 (B), SCCKN (C), and HSY (D). Cells were incubated with concentrations of 0 (control), 10, 25, 50, $100 \mu \mathrm{M}$ of ZOL for $72 \mathrm{~h}$, and cell proliferation was determined by WST-8 assay. Data represent cell numbers during treatment relative to control untreated cells $(100 \%)$. Values are the means \pm SD of three independent experiments.

Cell lines and cell culture. Human OSCC cell lines, HSC3 (poorly differentiated), HSC4 (well differentiated) and SCCKN (moderately differentiated), and the human salivary adenocarcinoma cell line, $\mathrm{HSY}, 8$ were maintained at $37^{\circ} \mathrm{C}$ in a fully humidified incubator with $5 \% \mathrm{CO}_{2}$ atmosphere in Dulbecco's modified Eagle's medium (Nissui, Tokyo, Japan) supplemented with $10 \%$ fetal bovine serum (JRH, Lenexa, $\mathrm{KS}, \mathrm{USA}), 100 \mathrm{U} / \mathrm{ml}$ penicillin, $100 \mu \mathrm{g} / \mathrm{ml}$ streptomycin and $292 \mu \mathrm{g} / \mathrm{ml} \mathrm{L}$-glutamine. HSY cells were kindly provided by Dr Y. Miyamoto (Department of Oral and Maxillofacial Surgery, Tokushima University School of Dentistry).

Determination of cell proliferation in vitro. Tumor cell proliferation was measured using a Cell Counting Kit-8 (CCK-8) according to the manufacturer's instructions. The cells were seeded on 96-well flat-bottomed tissue culture plates at a concentration of $5 \times 10^{3}$ cells/well with complete culture medium and allowed to adhere to the plate overnight. Then the cells were incubated in the presence of 0 (control), $10,25,50$ and $100 \mu \mathrm{M}$ of ZOL for another $72 \mathrm{~h}$. After treatment, $10 \mu 1$ of WST-8 Solution Reagent was added to each well for $180 \mathrm{~min}$. The samples were directly measured photometrically using a Bio-Rad Model at $450 \mathrm{~nm}$ (Bio-Rad Lab, Richmond, CA, USA).

Caspase-3, -8, and -9 activation assay. A CPP32/Caspase-3, -8 and -9 Colorimetric Protease Assay Kit (MBL Co., Ltd.) was used to investigate the activation of caspase- $3,-8$ and -9 expression in ZOL-treated HSC-3 cells. The assay was performed according to the manufacturer's instructions after $72 \mathrm{~h}$ of incubation with 0 (control), 10, 25, 50 or $100 \mu \mathrm{M}$ of
ZOL. Caspase- $3,-8$ and -9 activation led to cleavage of the provided colorimetric substrates, which could be measured photometrically at $405 \mathrm{~nm}$ (Bio-Rad Lab).

Western blot analysis. Subconfluent HSC-3 cells were cultured in $60-\mathrm{mm}$ dishes with 0 (control), 10, 25, 50 or $100 \mu \mathrm{M}$ of ZOL for $72 \mathrm{~h}$. They were harvested and lysates extracted and equal amounts of protein $(10 \mu \mathrm{g})$ were separated by SDS-PAGE and transferred to PVDF membranes. Rabbit anti-human poly(ADP-ribose) polymerase (PARP) polyclonal antibody (1:500 dilution; Cell Signaling Technology, Danvers, MA), goat anti-Bcl-2 polyclonal antibody (N-19; 1:500 dilution; Santa Cruz Biotechnology, Santa Cruz, CA), rabbit anti-human Bid polyclonal antibody (1:500 dilution; R\&D Systems, Inc., Minneapolis, MN), and B-actin monoclonal antibody (1:500 dilution; AC15, Sigma, St. Louis, MO, USA) were used as the primary antibodies. Specific bands were detected with an enhanced chemiluminescence system (ECL Detection System; Amersham, UK).

Hoechst 33258 staining. To detect apoptotic cells, both adherent and floating cells were collected, which were fixed with $100 \mu 1$ of Clarke's fixative (ethanol:acetic acid $=3: 1$ ) for $5 \mathrm{~min}$ at $4^{\circ} \mathrm{C}$, allowed to dry in air onto glass slides and then stained with $1 \mathrm{mg} / \mathrm{ml}$ Hoechst 33258 for $10 \mathrm{~min}$ in the dark at room temperature. After staining, the cells were washed three times with distilled water for $5 \mathrm{~min}$ each and counted.

Flow cytometric analysis. For cell cycle analysis, subconfluent HSC3 cells were cultured in $60-\mathrm{mm}$ dishes with 0 (control), 25 and $100 \mu \mathrm{M}$ of ZOL for 24,48 and $72 \mathrm{~h}$. The 


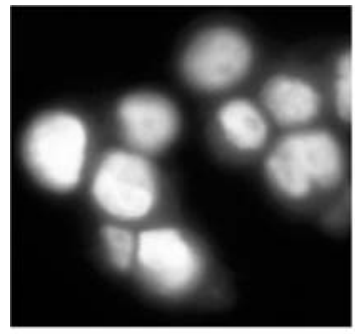

0

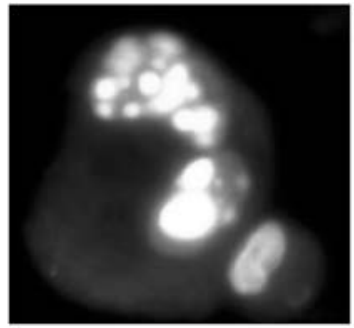

25

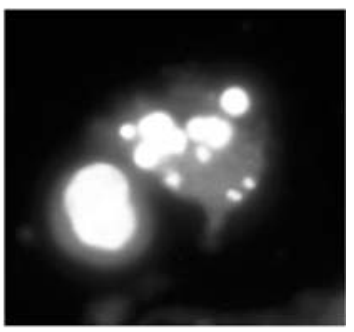

100

ZOL concentration $(\mu \mathrm{M})$

Figure 2. Fluorescent microscopic analysis shows apoptotic morphology of HSC-3 cells treated with a variety of concentrations of ZOL and stained with Hoechst 33258.

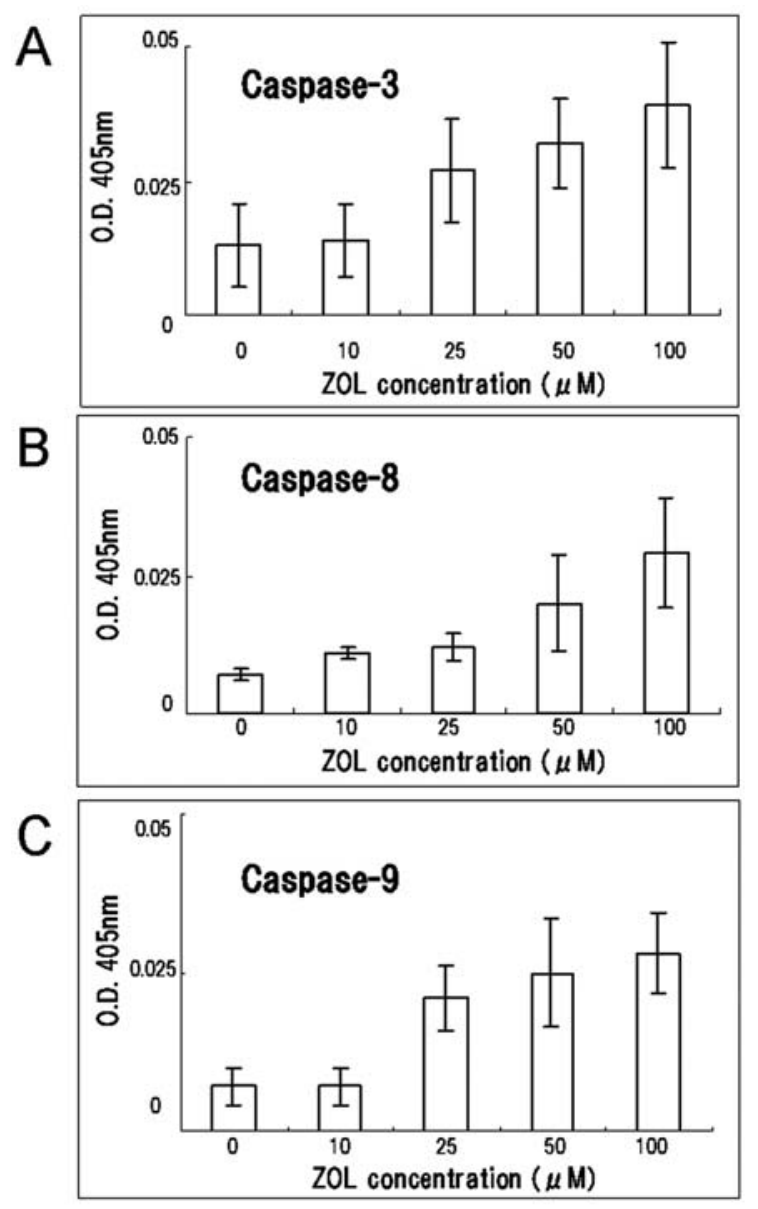

Figure 3. Colorimetric assay of caspase-3, $-8,-9$ activation. The activity of caspase-3, -8, -9 was increased in HSC-3 cells treated with ZOL for $72 \mathrm{~h}$. Values are the means \pm SD of three independent experiments.

cells were trypsinized, fixed in $70 \%$ ice-cold ethanol, and stored at $4^{\circ} \mathrm{C}$ for $72 \mathrm{~h}$. After fixation, cells were suspended in $100 \mu 1$ phosphate-citrate buffer $\left(0.19 \mathrm{M} \mathrm{Na}_{2} \mathrm{HPO}_{4}, 4 \mathrm{mM}\right.$ citric acid) and incubated for $30 \mathrm{~min}$ at room temperature, and then resuspended in $1 \mathrm{ml}$ of PBS containing $10 \mu \mathrm{g} / \mathrm{ml}$ of propidium iodide (PI) and $10 \mu \mathrm{g} / \mathrm{ml}$ of RNase. The PI stained cell samples were analyzed using FACSCalibur (BeckmanCoulter Epics Altra) and examined to determine the proportion of the population of cells in sub-G1, G0/G1, S and G2/M phases of the cell cycle.

\section{Results}

Zoledronic acid inhibits growth of oral cancer cells. We used the WST-8 assay to investigate the growth inhibitory effect of ZOL on oral cancer cells. ZOL (10-100 $\mu \mathrm{M})$ inhibited cell growth of all four oral cancer cell lines in a concentrationdependent manner. HSC-3, which is a poorly differentiated human OSCC cell line with a potential for high lymph node metastasis, and ZOL inhibited most effectively the proliferation of HSC-3 of the four oral cancer cell lines (Fig. 1). HSC-3 cells were studied in the following experiments.

Induction of apoptosis. We performed DNA staining of ZOLtreated HSC-3 cells using Hoechst 33258 staining. Fluorescent microscopic analysis demonstrated apoptotic cells by the presence of condensation and segmentation of the nuclei in HSC-3 cells treated with a variety of concentrations of ZOL (Fig. 2).

Caspase-3, -8 and -9 activation assay. The activity of caspase-3, -8 and -9 in HSC-3 cells treated with ZOL at a variety of concentrations increased in dose-dependent manner after $72 \mathrm{~h}$ (Fig. 3). Therefore, the activation of caspase-3, -8 and -9 correlated with the induction of apoptosis.

Western blot analysis. Additionally, we performed Western blot analysis to demonstrate PARP activity with inducted apoptosis by ZOL. We screened whole protein extracts from HSC-3 treated ZOL. PARP is a representative substrate for the effector caspase, and its cleavage is a marker of caspasedependent apoptosis (16). PARP cleavage could be detected in proteins extracted from HSC-3 cells treated with ZOL for $72 \mathrm{~h}$, indicating that the decrease in viable cells after $\mathrm{ZOL}$ treatment was accompanied due to an increase in tumor cell apoptosis (Fig. 4). Caspase- 8 is known to activate the proapoptotic Bcl-2 family member Bid by cleavage, so we also analyzed the amount of full length Bid protein in whole cell extracts. While $25 \mu \mathrm{M}$ of $\mathrm{ZOL}$ reduced the amount of Bid protein, $100 \mu \mathrm{M}$ of $\mathrm{ZOL}$ reduced the amount of full length Bid to almost undetectable levels. In addition, we analyzed the same whole cell extracts for expression of antiapoptotic Bcl-2 family members. Bcl-2 levels decreased substantially in the ZOL treated groups. These findings suggest that ZOL induced apoptosis of HSC-3 through the caspase $-3,-8$ and -9 pathway. 


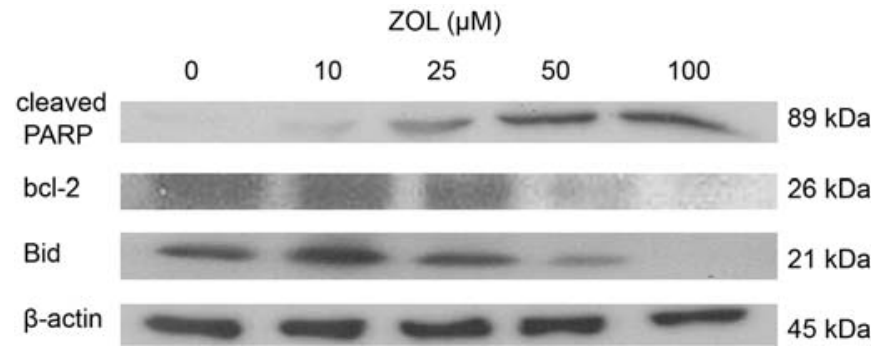

Figure 4. Protein expression in HSC-3 cells treated with ZOL. HSC-3 cells were incubated with ZOL for $72 \mathrm{~h}$, and protein expression was analyzed by Western blotting.

Cell cycle distribution. We performed flow cytometry analysis to investigate the cell cycle and apoptosis of HSC-3 cells after ZOL treatment. HSC-3 cells were treated with 25 and $100 \mu \mathrm{M}$ of ZOL for 24,48 and $72 \mathrm{~h}$. ZOL treatment increased the number of cells in sub $\mathrm{G} 1$ and $\mathrm{S}$ phase, and decreased the number of cells in G0/G1 and G2/M phase in a time- and concentration-dependent manner (Fig. 5, Table I).

\section{Discussion}

This study suggests that ZOL inhibited cell proliferation and induced apoptosis in oral cancer cell lines. Our study demonstrated that ZOL had a direct antitumor effect, in addition to the inhibition of osteoclast-mediated bone invasion in oral cancer. This is the first study to show that ZOL has antitumor effects on cultured oral cancer cell lines.

The mechanism of action of nitrogen-containing BPs is thought to be via inhibition of the activity of farnesyl
Table I. The population of cell cycle in HSC-3 (\%).

\begin{tabular}{cccc}
\hline & Control & ZOL $(25 \mu \mathrm{M})$ & hZOL $(100 \mu \mathrm{M})$ \\
\hline subG1 & & & \\
$24 \mathrm{~h}$ & 2.2 & 14.2 & 10.1 \\
$48 \mathrm{~h}$ & 5.3 & 35.5 & 29.7 \\
$72 \mathrm{~h}$ & 3.5 & 35.8 & 42.8 \\
$\mathrm{G} 0 / \mathrm{G} 1$ & & & \\
$24 \mathrm{~h}$ & 58.0 & 43.8 & 46.6 \\
$48 \mathrm{~h}$ & 71.5 & 26.8 & 33.3 \\
$72 \mathrm{~h}$ & 68.0 & 26.6 & 22.0 \\
$\mathrm{~S}$ & & & \\
$24 \mathrm{~h}$ & 23.4 & 24.6 & 36.4 \\
$48 \mathrm{~h}$ & 11.8 & 26.0 & 30.3 \\
$72 \mathrm{~h}$ & 17.1 & 30.8 & \\
$\mathrm{G} 2 / \mathrm{M}$ & & & 6.9 \\
$24 \mathrm{~h}$ & 16.4 & 17.4 & 5.5 \\
$48 \mathrm{~h}$ & 11.4 & 11.7 & 4.9 \\
$72 \mathrm{~h}$ & 11.4 & 8.7 & \\
\hline
\end{tabular}

diphosphate (FPP) synthase and geranylgeranyl diphosphate (GGPP) synthase, which are part of the mevalonate pathway, resulting in the inhibition of prenylation of small GTP proteins such as Ras, Rap1A, and Rho, $(17,18)$ which then act as antitumor effectors. Recently, BPs have been shown to have direct antitumor effects in multiple types of cancer cells in vitro and in vivo (12-15). It has been shown that admini-
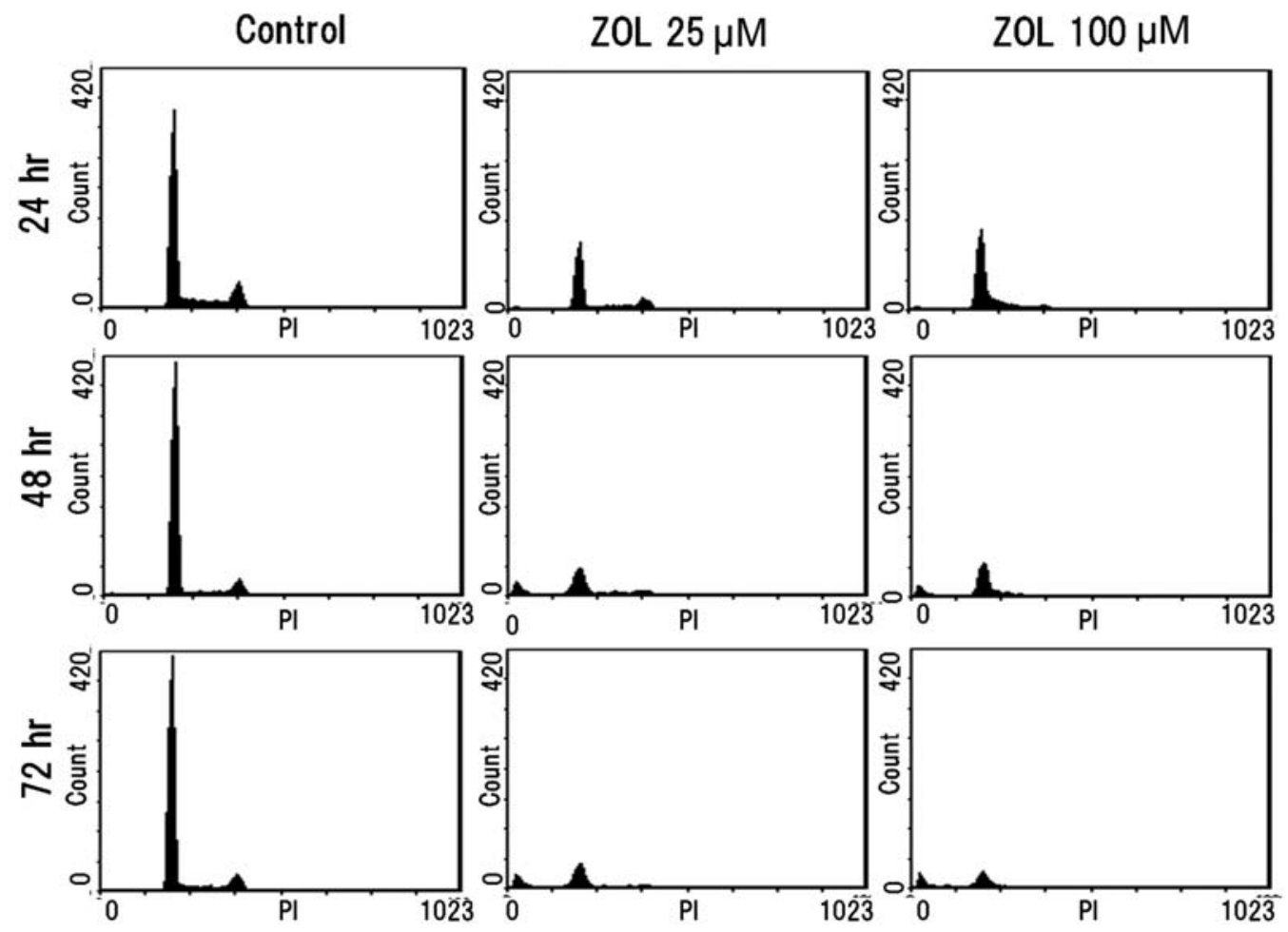

Figure 5. Flow cytometric analysis of DNA content in HSC-3 cells treated with of ZOL for 24, 48, or $72 \mathrm{~h}$. 
stration of BPs to patients with prostate cancer with bone metastases improves pain and tumor markers clinically (19).

Apoptosis requires the activation of caspases, which can be divided into initiator caspases and effector caspases. It is well known that there are many signal transduction pathways in apoptosis $(20,21)$. Activation of caspase-3, a component of the downstream of apoptosis pathway, is essential for the induction of apoptosis (20). Cleavage of PARP, an endogenous substrate of caspase-3, provides definite evidence of apoptosis (21). In the present study, caspase-3 was activated and cleavage of PARP was identified in the HSC-3 cells treated with ZOL by the caspase protease assay and Western blot analysis, confirming activation of the apoptosis signal pathway at the molecular level. Caspase-9 is the most critical upstream molecule of the apoptotic protease cascade. Bcl-2 is mainly located on the outer membrane of mitochondria and prevents the release of cytochrome $\mathrm{c}$, thereby preventing caspase activation $(22,23)$. Caspase- 8 activates downstream caspases by direct or indirect cleavage of Bid and induces cytochrome c release from mitochondria (24). The present study revealed the cleavage of these molecules in the HSC-3 cells treated with ZOL, suggesting that they participate in apoptosis induced by ZOL.

Several studies have indicated the benefits of the combined use of BPs with other cytotoxic agents $(15,26-28)$. Romani et al indicated that ZOL induces S-phase arrest in cholangiocarcinoma cells. Thus, ZOL could represent a reliable adjuvant chemotherapeutic agent which is able to sensitize cells to cytotoxic agents and/or radiation (29). Our flow cytometric analysis also showed that ZOL induced S-phase arrest in HSC-3 cells. This might suggest the synergistic effect of ZOL with other cytotoxic agents in oral carcinomas.

In conclusion, we confirmed that ZOL inhibits the proliferation of oral carcinoma cells in vitro by inducing apoptosis and/or cell cycle arrest. Therefore, it is suggested that ZOL treatment may be beneficial for patients with oral cancer. Further study should be conducted to clarify the mechanism of the antitumor effects of ZOL.

\section{References}

1. Momose F, Araida T, Negishi A, Ichijo H, Shioda S and Sasaki S: Variant sublines with different metastatic potentials selected in nude mice from human oral squamous cell carcinomas. J Oral Pathol Med 18: 391-395, 1989.

2. Sakai E and Tsuchida N: Most human squamous cell carcinomas in the oral cavity contain mutated p53 tumor-suppressor genes. Oncogene 7: 927-933, 1992.

3. Parkin DM, Läärä E and Muir CS: Estimates of the worldwide frequency of sixteen major cancers in 1980. Int J Cancer 41: 184-197, 1988

4. Day GL and Blot WJ: Second primary tumors in patients with oral cancer. Cancer 70: 14-19, 1992.

5. Carvalho AL, Nishimoto IN, Califano JA and Kowalski LP Trends in incidence and prognosis for head and neck cancer in the United States: a site-specific analysis of the SEER database. Int J Cancer 114: 806-816, 2004.

6. Jones AS, England J, Hamilton J, et al: Mandibular invasion in patients with oral and oropharyngeal squamous carcinoma. Clin Otolaryngol Allied Sci 22: 239-245, 1997.

7. Rao LP, Das SR, Mathews A, Naik BR, Chacko E and Pandey M: Mandibular invasion in oral squamous cell carcinoma: investigation by clinical examination and orthopantomogram. Int J Oral Maxillofac Surg 33: 454-457, 2004.

8. Okamoto M, Hiura K, Ohe G, et al: Mechanism for bone invasion of oral cancer cells mediated by interleukin-6 in vitro and in vivo. Cancer 89: 1966-1975, 2000
9. Fleisch H: Bisphophonates: a new class of drugs in diseases of bone and calcium metabolism, recent results. Cancer Res 116: 1-28, 1989.

10. Green JR: Chemical and biological prerequisites for novel bisphosphonate molecules: results of comparative preclinical studies. Semin Oncol 28: 4-10, 2001.

11. Rogers MJ, Watts DJ and Russell RG: Overview of bisphosphonates. Cancer 80: 1652-1660, 1997

12. Nakajima $\mathrm{H}$, Magae $\mathrm{J}$, Tsuruga $\mathrm{M}$, et al: Induction of mitochondria-dependent apoptosis through the inhibition of mevalonate pathway in human breast cancer cells by YM529, a new third generation bisphosphonate. Cancer Lett 253: 89-96, 2007.

13. Lee MV, Fong EM, Singer FR and Guenette RS: Bisphosphonate treatment inhibits the growth of prostate cancer cells. Cancer Res 61: 2602-2608, 2001.

14. Yuasa T, Nogawa M, Kimura S, et al: A third-generation bisphosphonate, minodronic acid (YM529), augments the interferon alpha/beta-mediated inhibition of renal cell cancer cell growth both in vitro and in vivo. Clin Cancer Res 11: 853-859, 2005.

15. Matsumoto S, Kimura S, Segawa H, et al: Efficacy of the thirdgeneration bisphosphonate, zoledronic acid alone and combined with anti-cancer agents against small cell lung cancer cell lines. Lung Cancer 47: 31-39, 2005.

16. Tewari M, Quan LT, O'Rourke K, et al: Yama/CPP32 $\beta$, a mammalian homolog of CED-3, is a CrmA-inhibitable protease that cleaves the death substrate poly(ADP-ribose) polymerase, Cell 81: 801-809, 1995.

17. Dunford JE, Rogers MJ, Ebetino FH, Phipps RJ and Coxon FP: Inhibition of protein prenylation by bisphosphonates causes sustained activation of Rac, Cdc42, and Rho GTPases. J Bone Miner Res 21: 684-694, 2006.

18. Van Beek E, Pieterman E, Cohen L, Löwik C and Papapoulos S: Nitrogen-containing bisphosphonates inhibit isopentenyl pyrophosphate isomerase/farnesyl pyrophosphate synthase activity with relative potencies corresponding to their antiresorptive potencies in vitro and in vivo. Biochem Biophys Res Commun 255: 491-494, 1999.

19. Asahi H, Mizokami A, Maeda Y, Komatsu K, Koshida K and Namiki M: Bisphosphonate therapy for hormone refractory prostate cancer with bone metastasis. J Urol 169: 281-282, 2003.

20. Roninson IB: Tumor senescence as a determinant of drug response in vivo. Drug Resist Update 5: 204-208, 2002.

21. Porter AG and Jänicke RU: Emerging roles of caspase- 3 in apoptosis. Cell Death Differ 6: 99-104, 1999.

22. Juan TS, McNiece IK, Argento JM, et al: Identification and mapping of Casp7, a cysteine protease resembling CPP32 beta, interleukin-1 beta converting enzyme, and CED-3. Genomics 40: 86-93, 1997.

23. Yang J, Liu X, Bhalla K, et al: Prevention of apoptosis by Bcl-2: release of cytochrome $\mathrm{c}$ from mitochondria blocked. Science 275: 1129-1132, 1997.

24. Kluck RM, Bossy-Wetzel E, Green DR and Newmeyer DD: The release of cytochrome $\mathrm{c}$ from mitochondria: a primary site for Bcl-2 regulation of apoptosis. Science 275: 1132-1136, 1997.

25. Sun J, Blaskovich MA, Knowles D, et al: Antitumor efficacy of a novel class of non-thiol-containing peptidomimetic inhibitors of farnesyltransferase and geranylgeranyltransferase I: combination therapy with the cytotoxic agents cisplatin, Taxol, and gemcitabine. Cancer Res 59: 4919-4926, 1999.

26. Karabulut B, Erten C, Gul MK, et al: Docetaxel/zoledronic acid combination triggers apoptosis synergistically through down-regulating antiapoptotic Bcl-2 protein level in hormonerefractory prostate cancer cells. Cell Biol Int 33: 239-246, 2009.

27. Murayama T, Kawasoe Y, Yamashita Y, et al: Efficacy of the third-generation bisphosphonate risedronate alone and in combination with anticancer drugs against osteosarcoma cell lines. Anticancer Res 28: 2147-2154, 2008.

28. Jagdev SP, Coleman RE, Shipman CM, Rostami HA and Croucher PI: The bisphosphonate, zoledronic acid, induces apoptosis of breast cancer cells: evidence for synergy with paclitaxel. Br J Cancer 84: 1126-1134, 2001.

29. Romani AA, Desenzani S, Morganti MM, La Monica S, Borghetti AF and Soliani P: Zoledronic acid determines S-phase arrest but fails to induce apoptosis in cholangiocarcinoma cells. Biochem Pharmacol 78: 133-141, 2009. 